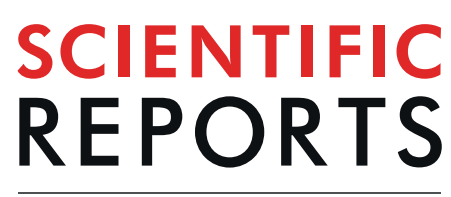

natureresearch

\title{
Level of obesity is directly associated with the clinical and functional consequences of knee osteoarthritis
}

\begin{abstract}
Benjamin Raud (i) ${ }^{1 *}$, Chloé Gay ${ }^{1,2,3}$, Candy Guiguet-Auclair ${ }^{2}$, Armand Bonnin ${ }^{1}$, Laurent Gerbaud ${ }^{2}$, Bruno Pereira ${ }^{4}$, Martine Duclos ${ }^{5}$, Yves Boirie ${ }^{6}$ \& Emmanuel Coudeyre ${ }^{1}$

Obesity is one of the most important risk factors of knee osteoarthritis (KOA), but its impact on clinical and functional consequences is less clear. The main objective of this cross-sectional study was to describe the relation between body mass index (BMI) and clinical expression of KOA. Participants with $\mathrm{BMI} \geq 25 \mathrm{~kg} / \mathrm{m}^{2}$ and KOA completed anonymous self-administered questionnaires. They were classified according to BMI in three groups: overweight (BMI $25-30 \mathrm{~kg} / \mathrm{m}^{2}$ ), stage I obesity (BMI $30-35 \mathrm{~kg} / \mathrm{m}^{2}$ ) and stage II/III obesity (BMI $\geq 35 \mathrm{~kg} / \mathrm{m}^{2}$ ). The groups were compared in terms of pain, physical disability, level of physical activity (PA) and fears and beliefs concerning KOA. Among the 391 individuals included, $57.0 \%$ were overweight, $28.4 \%$ had stage I obesity and $14.6 \%$ had stage II/III obesity. Mean pain score on a 10-point visual analog scale was 4.3 (SD 2.4), 5.0 (SD 2.6) and 5.2 (SD 2.3) with overweight, stage I and stage II/III obesity, respectively $(p=0.0367)$. The mean WOMAC function score (out of 100 ) was 36.2 (SD 20.1), 39.5 (SD 21.4) and 45.6 (SD 18.4), respectively $(p=0.0409)$. The Knee Osteoarthritis Fears and Beliefs Questionnaire total score (KOFBEO), daily activity score and physician score significantly differed among BMI groups $(p=0.0204, p=0.0389$ and $p=0.0413$, respectively), and the PA level significantly differed $(p=0.0219)$. We found a dose-response relation between $B M I$ and the clinical consequences of KOA. Strategies to treat KOA should differ by obesity severity. High PA level was associated with low BMI and contributes to preventing the clinical consequences of KOA.
\end{abstract}

Osteoarthritis (OA) is the most common joint disease and one of the most prevalent symptomatic health problems ${ }^{1}$. Knee osteoarthritis (KOA) leads to knee pain and altered joint function, with socioeconomic consequences $^{2}$. It generates a high proportion of health costs in many countries and has become a major public health issue. The health costs are directly related to KOA, such as knee replacement, or substantially by medication consumption ${ }^{3}$.

In the many studies investigating the risk factors of KOA, overweight and obesity remain the most determinant even though they are considered modifiable. A recent meta-analysis ${ }^{4}$ showed a 5 -unit increase in body mass index (BMI) associated with a 35\% increased risk of KOA (relative risk [RR]: 1.35; 95\% confidence interval [CI]: 1.21-1.51). BMI was positively associated with increased risk of KOA defined by plain radiography and/or clinical symptoms (RR: 1.25, 95\% CI: 1.17-1.35) and clinical surgery (RR: 1.54, 95\% CI: 1.29-1.83). Another study suggested a longitudinal association between weight gain and increased risk of symptomatic $\mathrm{OA}^{5}$. The Framingham study showed an association of decreased BMI by $\geq 2$ units at 10 years before examination and $50 \%$ decreased risk of OA for women ${ }^{6}$. In another cohort study ${ }^{7}$, a weight loss of $>10 \%$ could reduce the clinical consequences of OA, finding a dose-response association between weight loss and pain or articular function.

${ }^{1}$ Service de Médecine Physique et de Réadaptation, CHU Clermont-Ferrand, unité de nutrition humaine, INRA, Université Clermont Auvergne, F-63003, Clermont-Ferrand, France. ${ }^{2}$ Service de santé publique, CHU ClermontFerrand, F-63003, Clermont-Ferrand, France. ${ }^{3}$ Université Clermont Auvergne, CNRS, SIGMA Clermont Institut Pascal, F-63000, Clermont Ferrand, France. ${ }^{4}$ Délégation Recherche Clinique et Innovation, CHU Clermont-Ferrand, 63003, Clermont-Ferrand, France. ${ }^{5}$ Service de Médecine du Sport et explorations fonctionnelles, CHU ClermontFerrand, unité de nutrition humaine, INRA, Université Clermont-Auvergne, F-63003, Clermont-Ferrand, France. ${ }^{6}$ Service de Nutrition Clinique, CHU Clermont-Ferrand, unité de nutrition humaine, INRA, Université Clermont Auvergne, 63003, Clermont-Ferrand, France. *email: benjamin.raud@gmail.com 
Overweight and obesity are well known to increase the risk of KOA by mechanical load on weight-bearing joints ${ }^{8}$. However, obesity or metabolic syndrome also increase the risk of hand $\mathrm{OA}^{9}$. Hence, metabolic diseases, such as diabetes or metabolic syndrome, could have systemic effects on joints. A recent meta-analysis reported that type 2 diabetes mellitus may be a risk factor for OA whatever the location ${ }^{10}$. Few studies have explored the association between obesity stage and KOA consequences on disability. A recent study showed that waist circumference could be one of the main risk factors for limiting ambulation speed in adults with $\mathrm{KOA}^{11}$.

Regular physical activity (PA) as well as caloric restriction can reduce the clinical consequences of $\mathrm{KOA}^{12}$ and potentially contribute to weight loss. However, the impact of BMI on level of PA in people with OA is unknown. A recent study measured the level of PA in a normal-weight population versus unhealthy and healthy overweight and obese participants. PA was lower for unhealthy overweight and healthy and unhealthy obese participants than healthy overweight and normal-weight participants ${ }^{13}$. More specifically, a recent meta-analysis found that people with KOA were the least active according to PA guidelines ${ }^{14}$. Other studies of KOA suggest that being overweight or obese is associated with lower quality of life and higher risk of disability ${ }^{15}$ and may affect knee joint impact rates and cause incremental pain ${ }^{16}$. Also, overweight and obesity are risk factors for pain in the global population $^{17}$.

Despite obesity being a risk factor for KOA, we have few data on the association of obesity severity and its clin$\mathrm{ical}$ and functional consequences. This study aimed to describe the association between KOA and BMI gradation in terms of pain, physical disability, level of PA and fears and beliefs concerning KOA.

\section{Methods}

This study is part of a larger cross-sectional study of people with KOA older than 18 years of age that took place in France between September and November 2014 in 9 spa therapy resorts dedicated to OA. Every thermal establishment provided identical care for the patients, and procedures were similar for each center. For each patient, OA was the indication that led to prescribing spa therapy.

The study protocol was approved by the ethics committee of the university hospital of Clermont-Ferrand (medical ethics committee of South-East France Sud-Est 6, authorization no.: 90 2015/CE38) and was registered at ClinicalTrials.gov (NCT02681133). It was conducted in compliance with the Good Clinical Practices protocol and Declaration of Helsinki principles. All participants gave their verbal consent to participate after being informed about the study protocol.

Individuals were recruited on a voluntary basis and were included if they had symptomatic KOA (diagnosis of KOA confirmed by a physician, according to the criteria of the American College of Rheumatology ${ }^{18}$ ). Individuals younger than 18 years of age, with behavioral and comprehension difficulties and with bilateral total knee replacement were excluded. For the purpose of this study, data for only people with BMI $\geq 25 \mathrm{~kg} / \mathrm{m}^{2}$ were retained for analysis.

Participants were classified according to their BMI in three groups: overweight (BMI $25-30 \mathrm{~kg} / \mathrm{m}^{2}$ ), stage I obesity (BMI $\left.30-35 \mathrm{~kg} / \mathrm{m}^{2}\right)$ and stage II/III obesity $\left(\mathrm{BMI} \geq 35 \mathrm{~kg} / \mathrm{m}^{2}\right)$.

Data collection. Height and weight to calculate the BMI of each participant were measured by the physician in charge of the patient at inclusion. Other data were collected by use of an anonymous self-administered questionnaire. Posters were placed in each spa therapy resort to inform participants that research staff were available to help them complete the questionnaire if needed. Participants could complete their questionnaire at any time during their stay in the resort.

We collected sociodemographic data (sex, age) and clinical data: OA duration, joint replacement (knee and/ or hip), and comorbidities (diabetes, hypertension, renal failure, gastrointestinal bleeding, anxiety/depression, physical impairment limiting activity, cardiovascular disease) by declarative information based on Osteoarthritis Research Society International guidelines ${ }^{12}$. To avoid any misdeclaration, the pharmacological treatment reported by the participant was considered.

Pain during the last day and the most intense pain during the last month were assessed by a visual analog scale [VAS], from 0, no pain, to 10, very severe pain. Participants reported whether they were receiving treatment for OA pain and if they had another painful joint.

PA level was assessed by the short form of the International Physical Activity Questionnaire (IPAQ) ${ }^{19}$. We estimated continuous scores in metabolic equivalent minutes per week (MET-min/week) for vigorous, moderate, walking and total activity, as PA level (low, moderate or high).

The Western Ontario and McMaster Universities Osteoarthritis Index (WOMAC) was used to assess function in terms of physical disability. Only the function sub-scale was evaluated. The scale consists of 17 items that are summed to give a score, which was normalized to a 0 to 100 score. Higher scores indicate more severe impairment ${ }^{20}$.

Fears and beliefs about KOA were assessed by the 11-item Knee Osteoarthritis Fears and Beliefs Questionnaire $(\mathrm{KOFBeQ})$. Five scores were estimated: a total score and 4 sub-scores for fears and beliefs about activities of daily living, physicians, disease, and sports and leisure activities. Higher scores indicate greater fears and beliefs ${ }^{21}$.

Statistical analysis. Statistical analysis involved using SAS v9.4. Two-tailed $\mathrm{P}<0.05$ was considered statistically significant. No imputation method was used to replace missing data. Continuous data are presented as mean (SD) and categorical data as number (\%). The three BMI groups (overweight, stage I obesity, stage II/ III obesity) were compared in terms of sex, age, BMI, OA duration, joint replacement and comorbidities by the non-parametric Kruskal-Wallis test for continuous factors and chi-square or Fisher exact test for categorical factors. Generalized linear mixed models were used to compare the three BMI groups in terms of pain, WOMAC function score, IPAQ scores and KOFBeQ scores, with spa therapy resorts as a random effect and adjusted on potential confounders sex, age and number of comorbidities. 


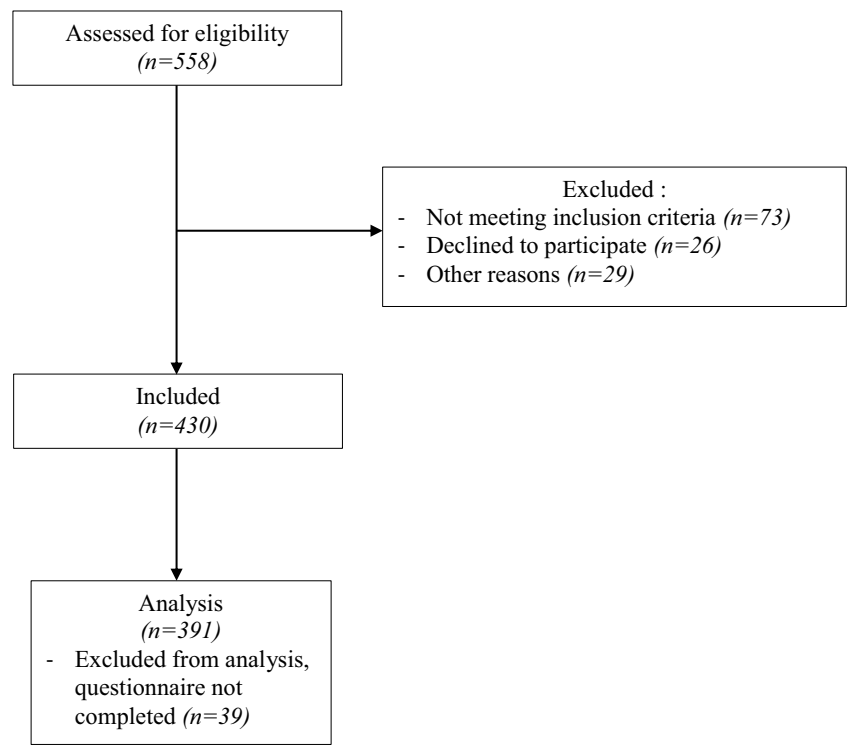

Figure 1. Flow diagram of participants in the study.

\begin{tabular}{|c|c|c|c|c|c|}
\hline & Overweight & Stage 1 & Stage II/III & Total & \\
\hline & $n=223$ & $\mathrm{n}=111$ & $\mathbf{n}=\mathbf{5 7}$ & $\mathbf{n}=391$ & P value \\
\hline Sex, n (\%) & & & & & 0.1188 \\
\hline Male & $70(31.4)$ & $32(28.8)$ & $10(17.5)$ & $112(28.6)$ & \\
\hline Female & $153(68.6)$ & $79(71.2)$ & $47(82.5)$ & $279(71.4)$ & \\
\hline Age (years), mean (SD) & $67.8(8.1)$ & $67.4(7.5)$ & $65.4(7.5)$ & $67.3(7.9)$ & 0.1566 \\
\hline BMI $\left(\mathrm{kg} / \mathrm{m}^{2}\right)$, mean $(\mathrm{SD})$ & $27.2(1.3)$ & $32.0(1.3)$ & $39.6(5.9)$ & $30.4(5.0)$ & $<0.0001$ \\
\hline OA duration (years), mean (SD) & $12.4(10.4)$ & $12.4(9.8)$ & $14.1(10.6)$ & $12.7(10.2)$ & 0.3320 \\
\hline Joint replacement (knee and/or hip), n (\%) & $40(18.5)$ & $26(24.5)$ & $10(19.6)$ & $76(20.4)$ & 0.4483 \\
\hline Total knee replacement & $22(10.2)$ & $15(14.2)$ & $6(11.8)$ & $43(11.5)$ & \\
\hline Total hip replacement & $18(8.3)$ & $11(10.4)$ & $4(7.8)$ & $33(8.8)$ & \\
\hline Traumatic or surgery knee history, n (\%) & $91(42.3)$ & $45(43.7)$ & $26(47.3)$ & $162(43.4)$ & 0.8025 \\
\hline \multicolumn{6}{|l|}{ Comorbidities, n (\%) } \\
\hline Diabetes & $21(9.4)$ & $23(20.7)$ & $11(19.3)$ & $55(14.1)$ & 0.0094 \\
\hline Hypertension & $77(34.5)$ & $57(51.4)$ & $32(56.1)$ & $166(42.5)$ & 0.0011 \\
\hline Renal failure & $7(3.1)$ & 0 & $1(1.8)$ & $8(2.0)$ & 0.1608 \\
\hline Gastrointestinal bleeding & $10(4.5)$ & $11(9.9)$ & $6(10.5)$ & $27(6.9)$ & 0.0928 \\
\hline Anxiety/depression & $32(14.3)$ & $20(18.0)$ & $17(29.8)$ & $69(17.6)$ & 0.0236 \\
\hline Physical impairment limiting activity & $29(13.0)$ & $15(13.5)$ & $9(15.8)$ & $53(13.6)$ & 0.8604 \\
\hline Cardiovascular disease & $41(18.4)$ & $20(18.0)$ & $8(14.0)$ & $69(17.6)$ & 0.7386 \\
\hline Number of comorbidities, mean (SD) & $1.1(1.1)$ & $2.4(1.2)$ & $2.6(1.1)$ & $1.7(1.3)$ & $<0.0001$ \\
\hline
\end{tabular}

Table 1. Characteristics at baseline for individuals with knee osteoarthritis (OA).

\section{Results}

Description of participants. We included 391 individuals with BMI $\geq 25 \mathrm{~kg} / \mathrm{m}^{2}$ (Fig. 1): 223 (57.0\%) were overweight, 111 (28.4\%) had stage I obesity, and 57 (14.6\%) had stage II/III obesity. The characteristics of participants are described in Table 1. BMI groups did not differ by sex, age, OA duration and joint replacement.

The mean number of comorbidities was 1.1 (SD 1.1) for overweight people as compared with 2.4 (SD 1.2) and 2.6 (SD 1.1) for stage I and stage II/III obesity groups $(\mathrm{p}<0.0001)$. The BMI groups significantly differed in terms of comorbidities for diabetes, hypertension and anxiety or depression: $9.4 \%, 20.7 \%$ and $19.3 \%$ of the overweight, stage I and stage II/III groups, respectively, were followed up for diabetes $(\mathrm{p}=0.0094) ; 34.5 \%, 51.4 \%$ and $56.1 \%$, respectively, reported hypertension $(\mathrm{p}=0.0011)$; and $14.3 \%, 18 \%$ and $29.8 \%$, respectively, reported anxiety or depression $(\mathrm{p}=0.0236)$. The BMI groups did not differ in terms of renal failure, gastrointestinal bleeding, physical impairment limiting activity, or cardiovascular disease. 


\begin{tabular}{|c|c|c|c|c|c|c|c|}
\hline & \multirow[b]{2}{*}{ Overweight } & \multirow[b]{2}{*}{ Stage I } & \multirow[b]{2}{*}{ Stage II/III } & \multirow[b]{2}{*}{ Total } & \multicolumn{3}{|l|}{ Pvalue } \\
\hline & & & & & $\begin{array}{l}\text { Stage I vs } \\
\text { Overweight }\end{array}$ & $\begin{array}{l}\text { Stage II/III vs } \\
\text { Overweight }\end{array}$ & $\begin{array}{l}\text { Stage II/ } \\
\text { III vs } \\
\text { Stage I }\end{array}$ \\
\hline $\begin{array}{l}\text { Pain during the last } \\
\mathbf{2 4} \text { hours }\left(\mathrm{VAS}^{\dagger} 0-10\right) \text {, } \\
\text { mean (SD) }\end{array}$ & $4.3(2.4)$ & $5.0(2.6)$ & $5.2(2.3)$ & $4.7(2.5)$ & 0.0356 & 0.0462 & 0.7454 \\
\hline $\begin{array}{l}\text { Most intense pain } \\
\text { during the last month } \\
\text { (VAS } 0-10) \text {, mean (SD) }\end{array}$ & $6.4(2.3)$ & $6.8(2.4)$ & $7.4(1.9)$ & $6.7(2.3)$ & 0.2973 & 0.0329 & 0.2241 \\
\hline $\begin{array}{l}\text { Treatment for pain due } \\
\text { to } \mathrm{OA}, \mathrm{n}(\%)\end{array}$ & $139(65.6 \%)$ & $71(68.3 \%)$ & $43(79.6 \%)$ & $253(68.4 \%)$ & 0.9807 & 0.2034 & 0.2286 \\
\hline \multicolumn{8}{|l|}{ Other painful joint, $\mathrm{n}(\%)$} \\
\hline Lumbar spine & $154(69.1 \%)$ & $80(72.1 \%)$ & $38(66.7 \%)$ & $272(69.6 \%)$ & 0.8967 & 0.4596 & 0.4386 \\
\hline Cervical spine & $129(57.8 \%)$ & $57(51.4 \%)$ & $36(63.2 \%)$ & $222(56.8 \%)$ & 0.1518 & 0.4619 & 0.0939 \\
\hline Hands & $109(48.9 \%)$ & $44(39.6 \%)$ & $29(50.9 \%)$ & $182(46.5 \%)$ & 0.0673 & 0.8041 & 0.2804 \\
\hline Shoulders & $107(48 \%)$ & $60(54.1 \%)$ & $29(50.9 \%)$ & $196(50.1 \%)$ & 0.4979 & 0.9994 & 0.6333 \\
\hline Hips & $68(40.5 \%)$ & $43(38.7 \%)$ & $23(40.4 \%)$ & $134(34.3 \%)$ & 0.1924 & 0.2628 & 0.9281 \\
\hline
\end{tabular}

Table 2. Description of pain reported by participants. *Generalized linear mixed models with spa therapy resorts as a random effect and adjusted for sex, age and number of comorbidities. ${ }^{\dagger}$ VAS: visual analog scale (0, no pain; 10 , very severe pain).

According to the Osteoarthritis Research Society International (OARSI) phenotypes ${ }^{12}, 96.5 \%$ of stage II/III participants had polyarthritis with comorbidities profiles, as compared with $90.1 \%$ of stage I and $57.8 \%$ of overweight participants $(\mathrm{p}<0.0001)$.

Pain. After adjustment for sex, age and number of comorbidities, pain intensity during the last 24 hours increased significantly with BMI gradation $(\mathrm{p}=0.0367)($ Table 2$)$. For the most intense pain during the last month, only overweight and stage II/III groups differed significantly. Pain intensity during the last 24 hours was $>4 / 10$ for $46.8 \%$ of overweight individuals versus $60 \%$ for stage I individuals ( $\mathrm{p}=0.0493$ ) and $65.5 \%$ for stage II/ III individuals $(\mathrm{p}=0.0343)$. Overall, $79.6 \%$ of participants with stage II/III obesity reported receiving treatment for pain due to OA versus $68.3 \%$ and $65.6 \%$ of stage I and overweight participants $(p=0.4199)$.

Participants reported another painful joint (Table 2), with no significant difference between groups. Multiple-joint OA was reported by $91.5 \%, 90.1 \%$ and $96.5 \%$ of participants in overweight, stage I and stage II/III obesity groups, respectively.

Physical disability. The WOMAC function scores are described in Table 3. The BMI groups significantly differed in physical disability $(\mathrm{p}=0.0409)$. The stage II/III obesity group was significantly more impaired than the overweight group $(\mathrm{p}=0.0115)$.

Physical activity level. The IPAQ PA level and continuous score are described in Table 3. The PA level significantly differed among BMI groups $(\mathrm{p}=0.0219)$. The proportion of participants with low and moderate PA level increased with BMI gradation and the proportion with high PA level decreased with BMI gradation. The BMI groups significantly differed by IPAQ continuous scores in MET-min/week: moderate activity $(\mathrm{p}=0.0051)$, walking $(\mathrm{p}=0.0201)$, and total activity $(\mathrm{p}=0.0002)$. The walking and total activity continuous scores decreased with BMI gradation. Time spent sitting significantly differed among groups $(\mathrm{p}=0.0025)$.

The IPAQ moderate activity, walking and total activity continuous scores, such as time spent sitting, significantly differed between overweight and stage II/III obesity groups and between stage I and stage II/III obesity groups.

Fear and beliefs concerning KOA. The KOFBeQ scores are described in Table 3. The total score, daily activity score and physician score significantly differed among BMI groups $(\mathrm{p}=0.0204, \mathrm{p}=0.0389$ and $\mathrm{p}=0.0413$, respectively), with significantly higher scores for the stage II/III obesity group. The disease and sports or leisure activities scores did not differ between groups.

\section{Discussion}

This study describes the clinical consequences of KOA severity in a KOA population by level of obesity. We found a graded relation between obesity stages and clinical consequences of KOA. Indeed, the results showed a progressive increase between degree of obesity based on BMI and clinical consequences. Participants with higher BMI had higher pain scores, were more disabled and reported more often anxiety and depression, which agrees with previous studies ${ }^{22}$. In addition, the higher the obesity stage, the less the participant performed PA, which increases the risk of leading a sedentary lifestyle.

The relationship between obesity severity and OA onset has been largely described in the literature. But to our knowledge, this is the first study to describe the clinical consequences of KOA by degree of obesity. Indeed, most studies have determined these two components in all obese people but not by BMI category. Thus, given the size of our sample, we could distinguish overweight individuals from those with grade I or II obesity and higher. 


\begin{tabular}{|c|c|c|c|c|c|c|c|}
\hline & \multirow[b]{2}{*}{ Overweight } & \multirow[b]{2}{*}{ Stage 1} & \multirow[b]{2}{*}{ Stage II/III } & \multirow[b]{2}{*}{ Total } & \multicolumn{3}{|l|}{ Pvalue* } \\
\hline & & & & & $\begin{array}{l}\text { Stage I vs } \\
\text { Overweight }\end{array}$ & $\begin{array}{l}\text { Stage II/ } \\
\text { III vs } \\
\text { Overweight }\end{array}$ & \begin{tabular}{|l|} 
Stage \\
II/III vs \\
Stage I
\end{tabular} \\
\hline $\begin{array}{l}\text { WOMAC function } \\
\text { score } \\
(0-100) \text {, mean (SD) }\end{array}$ & $36.2(20.1)$ & $39.5(21.4)$ & $45.6(18.4)$ & $38.5(20.4)$ & 0.4468 & 0.0115 & 0.0703 \\
\hline $\begin{array}{l}\text { IPAQ physical } \\
\text { activity level, } \mathrm{n}(\%)\end{array}$ & & & & & 0.3770 & 0.0058 & 0.0523 \\
\hline Low & $40(18.5)$ & $18(17.3)$ & $15(27.3)$ & $73(19.5)$ & & & \\
\hline Moderate & $75(34.7)$ & $46(44.2)$ & $27(49.1)$ & $148(39.5)$ & & & \\
\hline High & $101(46.8)$ & $40(38.5)$ & $13(23.6)$ & $154(41.1)$ & & & \\
\hline \multicolumn{8}{|c|}{ IPAQ score (MET-min/week), mean (SD) } \\
\hline Vigorous activity $^{\dagger}$ & $2956.8(2388.7)$ & $2472.0(1945.8)$ & $2653.3(2679.6)$ & $2803.7(2297.0)$ & 1 & 1 & 1 \\
\hline Moderate activity & $1703.2(1338.7)$ & $1829.1(1543.6)$ & $1100.0(1010.1)$ & $1645.0(1368.6)$ & 0.8521 & 0.0020 & 0.0035 \\
\hline Walking & $1373.4(1116.5)$ & $1357.9(1261.1)$ & $942.1(1001.5)$ & $1312.1(1149.6)$ & 0.4067 & 0.0053 & 0.0403 \\
\hline Total activity & $3627.5(2926.4)$ & $3249.7(2602.3)$ & $2094.6(1832.1)$ & $3292.7(2745.2)$ & 0.1617 & $<0.0001$ & 0.0040 \\
\hline $\begin{array}{l}\text { IPAQ time spent } \\
\text { sitting (min/week), } \\
\text { mean (SD) }\end{array}$ & $276.5(141.7)$ & $283.5(132.7)$ & $351.4(186.2)$ & $289.8(149.0)$ & 0.4970 & 0.0006 & 0.0072 \\
\hline \multicolumn{8}{|c|}{ KOFBeQ scores, mean (SD) } \\
\hline Total score & $41.5(22.7)$ & $45.9(23.1)$ & $52.4(20.6)$ & $44.4(22.8)$ & 0.1843 & 0.0064 & 0.1248 \\
\hline $\begin{array}{l}\text { Activities of daily } \\
\text { living }\end{array}$ & $8.8(7.7)$ & $9.9(8.4)$ & $12.4(8.5)$ & $9.6(8.1)$ & 0.3694 & 0.0111 & 0.0874 \\
\hline Physician & $17.1(10.9)$ & $19.6(10.6)$ & $21.3(10.2)$ & $18.4(10.8)$ & 0.0921 & 0.0226 & 0.3858 \\
\hline Disease & $7.1(6.4)$ & $7.6(5.8)$ & $8.1(5.1)$ & $7.4(6.1)$ & 0.6257 & 0.3474 & 0.6084 \\
\hline $\begin{array}{l}\text { Sports or leisure } \\
\text { activities }\end{array}$ & $8.5(6.3)$ & $9.0(6.0)$ & $10.4(5.5)$ & $8.9(6.1)$ & 0.5725 & 0.0585 & 0.1841 \\
\hline
\end{tabular}

Table 3. Description of WOMAC, IPAQ and KOFBeQ scores. *Generalized linear mixed models with spa therapy resorts as a random effect and adjusted for sex, age and number of comorbidities. ${ }^{\dagger}$ Statistical test could not be used because of small numbers in stage II/III obesity group.

Another strength of this study is the amount of data collected. Indeed, a large number of clinical variables were analyzed, which provided a broader picture when assessing daily life consequences on KOA.

The three obesity groups did not differ in location of pain. These findings agrees with the hypothesis of a "chronic micro-inflammatory state" that in conjunction with weight could play a major role in the initiation and perpetuation of $\mathrm{OA}^{23}$. Weight loss would be the best way to decrease chronic inflammation by reducing inflammatory mediators ${ }^{24}$ and also reduce mechanical load on bearing joints. Individuals with high BMI are at increased risk of metabolic syndrome, which is based on the co-occurrence of multiple risk factors (hypertension, high lipid levels) or type 2 diabetes mellitus or coronary heart disease ${ }^{25,26}$. Insulin resistance and micro-inflammation play a role in the development of chronic lesions. Micro-inflammation involved in the initiation and perpetuation of KOA is linked to level of insulin resistance ${ }^{23}$, and insulin resistance is associated with the location and proportion of fat mass ${ }^{27}$. Losing fat mass could play a major role in decreasing this micro-inflammation and reducing the clinical consequences of KOA.

We found the same gradual response between BMI and VAS pain score in the last 24 hours, which suggests higher pain for people with severe obesity and lower pain for overweight people. This finding may explain why weight loss may be directly associated with pain level ${ }^{28}$ and that the strategic approach to decrease pain could allow individuals to do more exercise. A recent study showed that in women with OA, disease-related pain was positively associated with cortisol production, particularly with greater pain intensity ${ }^{29}$. Pain is a potential stressor and activator of the hypothalamic-pituitary-adrenal axis, which has been related to increased visceral obesity ${ }^{30}$.

Strategies to control pain is a great part of the therapeutic proposition because it is a barrier to weight loss and PA. The psychological impact of obesity can be a barrier to PA and associated with severity of obesity. It could explain the association between BMI and the frequency of reported anxiety or depression. Strategies to increase the level of PA cannot be the same with different psychological profiles ${ }^{31}$, which emphasizes the need for personalized medicine.

PA or rehabilitation is widely recognized as one of the first non-pharmacological lines of treatment for OA and is recommended for all patients ${ }^{12}$. This study demonstrated that disability in patients with KOA, based on WOMAC function score, was associated with severity of obesity. With increasing obesity stage, OA increasingly led to altered function, thereby reducing the amount of PA performed, even though PA helps to improve function. Proposing PA as the first treatment aims to decrease fat mass, increase insulin sensitivity and decrease pain and micro-inflammation. However, we cannot expect severely obese individuals to do the same amount of PA as other people because they require psychological reinsurance. We found presence of anxiety and depression associated with BMI severity. This mental association with BMI severity should be more explored in future research, using validated instruments such as the Hospital Anxiety and Depression Scale (HADS) ${ }^{32}$ that evaluated the severity of anxiety and depression symptomatology. Obesity severity might be a stress factor recognized as a cardiovascular risk. 
Concerning the representativeness of our sample, the individuals we studied are representative of samples studied in the literature ${ }^{32}$ and because of the high number of participants $(n=391)$, many different phenotypes of KOA were included. Indeed, the mean age was 67.3 years, and $71 \%$ were women. The mean WOMAC function score was 38.5. Our population was close in terms of age, sex and function to the 915 patients in the Tubach et al. study ${ }^{32}$.

The main limitation of our study is that the level of PA was based on declarative and subjective reports. This could lead to discuss validity and significance of our results. However IPAQ is an international validated questionnaire and assesses both PA and sedentary time, ${ }^{33}$ although it overestimates $\mathrm{PA}^{34}$. We found a linear relation between BMI and PA, but the relation may be overestimated ${ }^{35}$. Assessing the level of PA with objective measures such as an accelerometer would be interesting but still expensive. The fact that other parameters, such as OA duration, are self-reported could be a limitation of the study. Comorbidities and joint replacement could be considered reliable when reported by the patient. Knee OA criteria based on ACR criteria were verified by the physician in charge of the patient before starting the program in the spa resort for limiting this bias. Parameters such as OA duration did not significantly differ among groups. Another limitation concerns a reverse causality relation between outcomes and overweight and obesity. It is probably better to consider this as a single association rather than a real reverse causality. It is possible that our results were predictable but to our knowledge the relationship between obesity severity and PA level and several other patients reported outcomes had never been definitively demonstrated before. By the way, it is really important for every day practice to take in count obesity severity regarding PA management and rehabilitation ${ }^{36}$ for OA management.

Other objective data are missing in this study and would be pertinent to screen, such as body composition with distribution of mass. PA level depends on obesity severity, but the relation between fat mass index and PA could be assessed.

\section{Conclusion}

We found level of obesity directly associated with clinical consequences of KOA, with a gradual dose-response relation by increasing BMI. High PA level was associated with low BMI and contributed to preventing the clinical consequences of KOA. The role of body fat mass in terms of clinical benefits of PA could be studied.

Received: 19 December 2018; Accepted: 31 January 2020;

Published online: 27 February 2020

\section{References}

1. Palazzo, C., Nguyen, C., Lefevre-Colau, M.-M., Rannou, F. \& Poiraudeau, S. Risk factors and burden of osteoarthritis. Ann Phys Rehabil Med 59, 134-138 (2016)

2. Puig-Junoy, J. \& Ruiz Zamora, A. Socio-economic costs of osteoarthritis: a systematic review of cost-of-illness studies. Semin. Arthritis Rheum. 44, 531-541 (2015).

3. Bitton, R. The economic burden of osteoarthritis. Am J Manag Care 15, S230-235 (2009).

4. Reyes, C. et al. Association Between Overweight and Obesity and Risk of Clinically Diagnosed Knee, Hip, and Hand Osteoarthritis: A Population-Based Cohort Study. Arthritis \& Rheumatology (Hoboken, N.J.) 68, 1869-1875 (2016).

5. Felson, D. T. et al. Risk factors for incident radiographic knee osteoarthritis in the elderly: the Framingham Study. Arthritis Rheum. 40, 728-733 (1997).

6. Felson, D. T., Zhang, Y., Anthony, J. M., Naimark, A. \& Anderson, J. J. Weight loss reduces the risk for symptomatic knee osteoarthritis in women. The Framingham Study. Ann. Intern. Med. 116, 535-539 (1992).

7. Riddle, D. L. \& Stratford, P. W. Body weight changes and corresponding changes in pain and function in persons with symptomatic knee osteoarthritis. A cohort study. Arthritis Care Res (Hoboken) 65, 15-22 (2013).

8. Puenpatom, R. A. \& Victor, T. W. Increased prevalence of metabolic syndrome in individuals with osteoarthritis: an analysis of NHANES III data. Postgrad Med 121, 9-20 (2009).

9. Dahaghin, S., Bierma-Zeinstra, S. M. A., Koes, B. W., Hazes, J. M. W. \& Pols, H. A. P. Do metabolic factors add to the effect of overweight on hand osteoarthritis? The Rotterdam Study. Annals of the Rheumatic Diseases 66, 916-920 (2007)

10. Louati, K., Vidal, C., Berenbaum, F. \& Sellam, J. Association between diabetes mellitus and osteoarthritis: systematic literature review and meta-analysis. RMD Open 1, e000077 (2015).

11. Gill, S. V. et al. The association of waist circumference with walking difficulty among adults with or at risk of knee osteoarthritis: the Osteoarthritis Initiative. Osteoarthr. Cartil. 25, 60-66 (2017).

12. McAlindon, T. E. et al. OARSI guidelines for the non-surgical management of knee osteoarthritis. Osteoarthr. Cartil. 22, 363-388 (2014).

13. Bell, J. A. et al. Healthy obesity and objective physical activity. Am. J. Clin. Nutr. 102, 268-275 (2015).

14. Wallis, J. A., Webster, K. E., Levinger, P. \& Taylor, N. F. What proportion of people with hip and knee osteoarthritis meet physical activity guidelines? A systematic review and meta-analysis. Osteoarthr. Cartil. 21, 1648-1659 (2013).

15. Batsis, J. A. et al. Impact of obesity on disability, function, and physical activity: data from the Osteoarthritis Initiative. Scand. J. Rheumatol. 44, 495-502 (2015).

16. Marks, R. Obesity profiles with knee osteoarthritis: correlation with pain, disability, disease progression. Obesity (Silver Spring) 15, 1867-1874 (2007).

17. Janke, E. A., Collins, A. \& Kozak, A. T. Overview of the relationship between pain and obesity: What do we know? Where do we go next? J Rehabil Res Dev 44, 245-262 (2007).

18. Altman, R. et al. Development of criteria for the classification and reporting of osteoarthritis. Classification of osteoarthritis of the knee. Diagnostic and Therapeutic Criteria Committee of the American Rheumatism Association. Arthritis Rheum. 29, 1039-1049 (1986).

19. Rivière, F. et al. Reliability and validity of the French version of the global physical activity questionnaire. Journal of Sport and Health Science, https://doi.org/10.1016/j.jshs.2016.08.004 (2016)

20. Bellamy, N., Buchanan, W. W., Goldsmith, C. H., Campbell, J. \& Stitt, L. W. Validation study of WOMAC: a health status instrument for measuring clinically important patient relevant outcomes to antirheumatic drug therapy in patients with osteoarthritis of the hip or knee. J. Rheumatol. 15, 1833-1840 (1988).

21. Benhamou, M. et al. Development and validation of a questionnaire assessing fears and beliefs of patients with knee osteoarthritis: the Knee Osteoarthritis Fears and Beliefs Questionnaire (KOFBeQ). PLoS ONE 8, e53886 (2013). 
22. Li, H., George, D. M., Jaarsma, R. L. \& Mao, X. Metabolic syndrome and components exacerbate osteoarthritis symptoms of pain, depression and reduced knee function. Ann Transl Med 4 (2016).

23. Duclos, M. Osteoarthritis, obesity and type 2 diabetes: The weight of waist circumference. Ann Phys Rehabil Med 59, 157-160 (2016).

24. Bartels, E. M. et al. Effect of a 16 weeks weight loss program on osteoarthritis biomarkers in obese patients with knee osteoarthritis: a prospective cohort study. Osteoarthr. Cartil. 22, 1817-1825 (2014).

25. Alberti, K. G. M. M. et al. Harmonizing the metabolic syndrome: a joint interim statement of the International Diabetes Federation Task Force on Epidemiology and Prevention; National Heart, Lung, and Blood Institute; American Heart Association; World Heart Federation; International Atherosclerosis Society; and International Association for the Study of Obesity. Circulation 120, 1640-1645 (2009).

26. Malik, S. et al. Impact of the metabolic syndrome on mortality from coronary heart disease, cardiovascular disease, and all causes in United States adults. Circulation 110, 1245-1250 (2004).

27. Lalia, A. Z. et al. Predictors of Whole-Body Insulin Sensitivity Across Ages and Adiposity in Adult Humans. J. Clin. Endocrinol. Metab. 101, 626-634 (2016)

28. Gersing, A. S. et al. Progression of cartilage degeneration and clinical symptoms in obese and overweight individuals is dependent on the amount of weight loss: 48-month data from the Osteoarthritis Initiative. Osteoarthr. Cartil. 24, 1126-1134 (2016).

29. Carlesso, L. C., Sturgeon, J. A. \& Zautra, A. J. Exploring the relationship between disease-related pain and cortisol levels in women with osteoarthritis. Osteoarthritis and Cartilage 24, 2048-2054 (2016).

30. Duclos, M., Marquez Pereira, P., Barat, P., Gatta, B. \& Roger, P. Increased cortisol bioavailability, abdominal obesity, and the metabolic syndrome in obese women. Obes. Res. 13, 1157-1166 (2005).

31. Gay, C., Chabaud, A., Guilley, E. \& Coudeyre, E. Educating patients about the benefits of physical activity and exercise for their hip and knee osteoarthritis. Systematic literature review. Ann Phys Rehabil Med 59, 174-183 (2016).

32. Herrmann, C. International experiences with the Hospital Anxiety and Depression Scale-a review of validation data and clinical results. J Psychosom Res 42, 17-41 (1997).

33. Tubach, F. et al. Evaluation of clinically relevant states in patient reported outcomes in knee and hip osteoarthritis: the patient acceptable symptom state. Ann Rheum Dis 64, 34-37 (2005).

34. Rütten, A. et al. Using different physical activity measurements in eight European countries. Results of the European Physical Activity Surveillance System (EUPASS) time series survey. Public Health Nutr 6, 371-376 (2003).

35. Ainsworth, B. E. et al. Comparison of the 2001 BRFSS and the IPAQ Physical Activity Questionnaires. Med Sci Sports Exerc 38, 1584-1592 (2006).

36. Brosseau, L. et al. Ottawa Panel evidence-based clinical practice guidelines for the management of osteoarthritis in adults who are obese or overweight. Phys Ther 91, 843-861 (2011).

\section{Acknowledgements}

Nicolas Andant, Christine Levyckyj, Christine Flouzat, Anne-Cécile Fournier and Anna Goldstein: help in study management. Patients and employees of Thermal SPA Center: Bourbon Lancy, Bourbon l'Archambault, Chatel Guyon, Chaudes Aigues, Evaux les Bains, Le Mont Dore, Néry Les Bains, Royat and Vichy. This work is financially supported by the "Innovatherm cluster" and "Clermont-Ferrand Communaute". The "Auvergne region" for the "Cluster network research grant" allowed us to recruit a PhD student to carry out this study.

\section{Author contributions}

Raud B.; drafting of the article, ensured the accuracy of the data and analysis. Gay C.; collection and assembly of data. Guiguet-Auclair C.; statistical expertise, analysis and interpretation of data. Bonnin A.; ensured the accuracy of the data and analysis. Gerbaud L.; statistical expertise, analysis and interpretation of data. Pereira B.; statistical expertise, analysis and interpretation of data. Duclos M.; ensured the accuracy of the data and analysis. Boirie Y.; conception and design, ensured the accuracy of the data and analysis. Coudeyre E.; conception and design, ensured the accuracy of the data and analysis, drafted of the article. All authors; final approval of the article.

\section{Competing interests}

The authors declare no competing interests.

\section{Additional information}

Correspondence and requests for materials should be addressed to B.R.

Reprints and permissions information is available at www.nature.com/reprints.

Publisher's note Springer Nature remains neutral with regard to jurisdictional claims in published maps and institutional affiliations.

Open Access This article is licensed under a Creative Commons Attribution 4.0 International License, which permits use, sharing, adaptation, distribution and reproduction in any medium or format, as long as you give appropriate credit to the original author(s) and the source, provide a link to the Creative Commons license, and indicate if changes were made. The images or other third party material in this article are included in the article's Creative Commons license, unless indicated otherwise in a credit line to the material. If material is not included in the article's Creative Commons license and your intended use is not permitted by statutory regulation or exceeds the permitted use, you will need to obtain permission directly from the copyright holder. To view a copy of this license, visit http://creativecommons.org/licenses/by/4.0/.

(c) The Author(s) 2020 